\title{
Association between circadian variation of heart rate and mortality among critically ill patients: a retrospective cohort study
}

\author{
Jingjing Zhang, Linyun Du, Jiamei Li, Ruohan Li, Xuting Jin, Jiajia Ren, Ya Gao and Xiaochuang Wang*
}

\begin{abstract}
Background: Heart rate (HR) related parameters, such as HR variability, $H R$ turbulence, resting $H R$, and nighttime mean HR have been recognized as independent predictors of mortality. However, the influence of circadian changes in HR on mortality remains unclear in intensive care units (ICU). The study is designed to evaluate the relationship between the circadian variation in HR and mortality risk among critically ill patients.

Methods: The present study included 4,760 patients extracted from the Multiparameter Intelligent Monitoring in Intensive Care II database. The nighttime mean HR/daytime mean HR ratio was adopted as the circadian variation in HR. According to the median value of the circadian variation in HR, participants were divided into two groups: group $A(\leq 1)$ and group B $(>1)$. The outcomes included ICU, hospital, 30-day, and 1-year mortalities. The prognostic value of HR circadian variation was investigated by multivariable logistic regression models and Cox proportional hazards models.
\end{abstract}

Results: Patients in group B $(n=2,471)$ had higher mortality than those in group $\mathrm{A}(n=2,289)$. Multivariable models revealed that the higher circadian variation in HR was associated with ICU mortality (odds ratio [OR], 1.393; 95\% confidence interval $[C l], 1.112-1.745 ; P=0.004)$, hospital mortality $(\mathrm{OR}, 1.393 ; 95 \% \mathrm{Cl}, 1.112-1.745 ; P=0.004)$, 30-day mortality (hazard ratio, 1.260; 95\% Cl, 1.064-1.491; $P=0.007$ ), and 1-year mortality (hazard ratio, 1.207; 95\% Cl, 1.057-1.378; $P=0.005)$, especially in patients with higher SOFA scores.

Conclusions: The circadian variation in HR might aid in the early identification of critically ill patients at high risk of associated with ICU, hospital, 30-day, and 1-year mortalities.

Keywords: Circadian variation, Heart rate, Mortality, Intensive care unit

\section{Background}

Heart rate (HR) is regulated by the autonomic nervous system, and therefore, the autonomic nervous system function could be reflected by HR variations, such as heart rate variability (HRV), heart rate turbulence (HRT), resting heart rate (RHR), and nighttime mean heart rate (NHR). Among them, HRV is measured by the variation

*Correspondence: dr_xc_wang@163.com

Department of Critical Care Medicine, the Second Affiliated Hospital

of Xi'an Jiaotong University, Xi'an, China in the beat-to-beat interval between consecutive heart beats to evaluate the autonomic nervous mediation of the cardiovascular system [1, 2]. Several studies have reported that the decrease in HRV was associated with impaired sympathetic modulation, which led to early inhospital deterioration of sepsis and multiple organ dysfunction syndrome (MODS), and a higher mortality in the intensive care unit (ICU) [3-10]. However, Monfredi et al. have put forward a novel controversial discussion about the exponential decay relationship between HR and HRV, that is, HRV is primarily dependent on HR, with HRV increasing when HR slows, and vice versa original author(s) and the source, provide a link to the Creative Commons licence, and indicate if changes were made. The images or other third party material in this article are included in the article's Creative Commons licence, unless indicated otherwise in a credit line to the material. If material is not included in the article's Creative Commons licence and your intended use is not permitted by statutory regulation or exceeds the permitted use, you will need to obtain permission directly from the copyright holder. To view a copy of this licence, visit http://creativecommons.org/licenses/by/4.0/. The Creative Commons Public Domain Dedication waiver (http://creativeco mmons.org/publicdomain/zero/1.0/) applies to the data made available in this article, unless otherwise stated in a credit line to the data. 
[11]. Therefore, HRV cannot be used in any simple way to assess the autonomic nerve activity to the heart. HRT describes the physiological short-term oscillation of beatto-beat intervals after spontaneous ventricular premature beats [12], which has been introduced as an autonomic predictor for cardiac mortality following myocardial infarction or heart failure $[12,13]$. Besides, there have been previous reports in literature that increased resting $H R$ can be associated with increased short-term and long-term mortality from critical illness [14-19]. Although the above parameters have been verified to have a higher predictive value for mortality, they either have their own limitations or ignore the circadian rhythm of the HR.

Most of physiological parameters, such as HR, blood pressure, spontaneous motor activity, cortisol, sleep cycles, the immune system, the autonomic nervous system, and body temperature follow 24-h stable circadian rhythms in healthy individuals [20]. However, these circadian rhythms may be interrupted or impaired by the loss of external zeitgebers when critically ill patients are often exposed to different degrees of artificial light, noise, continuous therapeutic intervention including ventilation, parenteral nutrition, and medications in the ICU [20-23]. Therefore, we took the circadian rhythms of HR into account to study the relationship between circadian variation of HR and mortality among critically ill patients admitted to the ICU in the Multiparameter Intelligent Monitoring in Intensive Care II (MIMIC-II) database.

\section{Methods}

\section{Study design}

This was an observational study conducted using individual medical information from the MIMIC-II database, which is maintained by the Laboratory for Computational Physiology at the Massachusetts Institute of Technology (MIT; Cambridge, MA) and contains de-identified data on patients hospitalized at an ICU at Beth Israel Deaconess Medical Center (Boston, MA) from 2001 to 2008 [24]. All procedures performed in studies involving human participants were in accordance with the ethical standards of the institutional research committee (Cardif Metropolitan University ethics committee-17/4/02R) and with the 1964 Helsinki Declaration and its later amendments or comparable ethical standards. Since the study did not impact clinical care and all protected health information was de-identified, the requirement for individual patient consent was waived by the Institutional Review Board of Beth Israel Deaconess Medical Center. All authors have attended the "protecting human subjects training" and obtained the certificate which permits access to the data.

\section{Date extraction}

Patient data were exacted from MIMIC-II (version 2.6) using SAS version 9.4 (SAS Institute, Cary, NC). The extracted data, including patient identifiers, demographics, clinical diagnoses, medications effecting HR, scoring systems, length of stay in ICU, and complete HR records within the first $24 \mathrm{~h}$ after ICU admission, were acquired from 2001 to 2008 at Beth Israel Deaconess Medical Center. Age, sex, and ethnicity were included in the demographics and clinical diseases were diagnosed according to the International Classification of Diseases-9 diagnoses (ICD, 9th Editor), which includes respiratory failure, renal failure, liver cirrhosis, shock, diabetes uncomplicated, diabetes complicated, acquired immune deficiency syndrome (AIDS), lymphoma, metastatic cancer, coagulopathy, rheumatoid arthritis, infection, poisoning, hypoferric anemia, and a series of cardiovascular diseases. Severity-of-illness scores systems, including the Simplified Acute Physiology Score-I (SAPS-I) score and Sequential Organ Failure Assessment (SOFA) score, were calculated using physiological measurements and clinical information according to published recommendations and accepted formulae [25]. The medications included catecholamine, $\beta$-blockers, sedatives, and opioid analgesics.

\section{Patient selection}

The data of a total of 4,760 adult patients were extracted from the MIMIC-II V2.6 database. These patients met the following characteristics: (1) single ICU admission; (2) the length of ICU stay $\geq 24 \mathrm{~h}$; (3) no history of cardiovascular diseases, including cardiac arrhythmias, cardiac arrest, hypertension, heart failure, and coronary heart disease, or no use of cardiac pacemaker due to any cause; (4) complete HR and covariate records; (5) no outliers in HR records. Outliers were defined as values exceeding the mean \pm 3 times the SD [26].

\section{Circadian rhythm of HR}

HR was measured using a bedside monitor (Component Monitoring System IntelliVue MP-70; Philips Healthcare, Andover, MA) during the first $24 \mathrm{~h}$ in the ICU. In the present study, we focused on differences between the mean nighttime and daytime HR. Thus, the circadian rhythm of HR is calculated as the mean nighttime $H R$ value divided by the mean daytime $H R$ value. Patients were divided into two groups according to the median of the circadian rhythm of HR: the lower circadian rhythm of HR group (group $A \leq 1$ ) and the higher circadian rhythm of HR group (group B $>1$ ). The mean daytime HR value was computed as the average of all HR values from 7 am to $11 \mathrm{pm}$, and the mean 
nighttime HR was the average of all HR values from $11 \mathrm{pm}$ to 7 am on the next day.

\section{Endpoints}

The primary outcome measures in our study were ICU mortality and hospital mortality. The secondary outcome measures were 30 -day mortality and 1-year mortality.

\section{Statistical analysis}

Continuous variables are presented as the mean with $\mathrm{SD}$ or median with interquartile ranges. The one-way analysis of variance (ANOVA), or Kruskal-Wallis test was used as appropriate. Categorical variables are presented as frequency with percentage and compared using the Chi-Square test. To assess the association of circadian variation of HR with the study outcomes, we used univariate and multivariable logistic regression models for ICU and hospital mortality, cox proportional hazards model for the 30-day and 1-year mortality. All variables in the Cox proportional hazards model must meet the proportional hazard assumption. The multivariable models were adjusted for the following factors: (1) unadjusted in Model 1; (2) age, sex, and ethnicity in Model 2; (3) Model 2 plus clinical diagnoses (including respiratory failure, renal failure, liver cirrhosis, shock, diabetes uncomplicated, diabetes complicated, AIDS, lymphoma, metastatic cancer, coagulopathy, rheumatoid arthritis, infection, poisoning, and hypoferric anemia) in Model 3; (4) Model 3 plus medication taking on day 1 (including sedatives, catecholamines, $\beta$-blockers, and opioid analgesics) in Model 4; (5) Model 4 plus the first SOFA and SAPS-I score after ICU admission in Model 5; (6) Model 5 plus length of stay in ICU in Model 6; (7) Model 6 plus the first 24-h average HR in Model 7. Besides, based on the median of the first SOFA score, all patients were divided into the low SOFA score (0-5) group and the high SOFA score (6-24) group. Logistic regression and Cox regression were used to evaluate the relationship between the circadian rhythm of HR and outcomes in the two subgroups. $P$ values of $<0.05$ were considered to be statistically significant. All statistical analyses were performed with the SPSS software package version 22.0 (IBM Corp., Armonk, NY).

\section{Results}

\section{Baseline characteristics}

The records of 4760 patients were included in this study. Most of the study population came from surgical ICU (40.3\%), followed by medical ICU (37.5\%) (Supplementary Table 1). There were no significant differences in age, sex, ethnicity, and clinical diseases between the lower circadian rhythm of HR group (group $A \leq 1$ ) and the higher circadian rhythm of HR group (group $B>1$ ). However, patients in group B had higher SOFA scores [5.00 (2.00, $8.00)$ vs. $4.00(2.00,7.00), P=0.001]$, SAPS-I scores [12.00 $(9.00,16.00)$ vs. $12.00(8.00,16.00), P=0.006]$, and length of stay in ICU $[2.52(1.69,4.96)$ vs. $2.31(1.54,4.26)$, $P=0.001$ ) than those in group A. Moreover, patients in group $B$ had a higher exposure rate for catecholamines $(10.8 \%$ vs. $8.7 \%, P=0.014)$ and opioid analgesics $(2.5 \%$ vs. $1.3 \%, P=0.002$ ) than those in group A (Table 1). Besides, the univariate analysis of factors associated ICU, hospital, 30-day and 1-year mortality was presented in the Supplementary Table 2 and Supplementary Table 3. Furthermore, compared to ICU survival group, the dead patients during ICU stay were also more serious, with higher SOFA score $[10.00(7.00,14.00)$ vs. $4.00(2.00,7.00)$, $P<0.001]$ and SAPS-I score $[19.00(15.00,23.00)$ vs. 12.00 $(8.00,15.00), P<0.001$ ] (Table 2$)$.

\section{Association of the circadian variation of $\mathrm{HR}$ with mortality} Patients in group B had higher ICU mortality $(9.6 \%$ vs. $6.6 \%, P<0.001)$, hospital mortality $(12.3 \%$ vs. $8.7 \%$; $P<0.001)$, 30-day mortality $(13.9 \%$ vs. $10.3 \%$; $P<0.001)$ and 1 -year mortality $(21.2 \%$ vs. $17.3 \%, P=0.001)$ than that in group A patients (Table 1 and Fig. 1). These trends were also verified by the logistic regression analysis and the Cox regression model. Taking group A as the reference, after adjusting for all covariates, including age, sex, ethnicity, ICD-9 diagnoses, medication usage on day 1 of admission to the ICU, the first SOFA score, the first SAPS-I score, length of stay in the ICU, and the first 24-h average HR, the logistic regression results showed that group $\mathrm{B}$, that is, the higher circadian variation of HR group was significantly associated with ICU mortality (odds ratio [OR], 1.393; 95\% confidence interval $[\mathrm{CI}], 1.112-1.745 ; P=0.004)$ and hospital mortality (OR, 1.393; 95\% CI, 1.112-1.745; $P=0.004)$. Similarly, after adjusting for the same variables, the Cox proportional hazards model also showed that the higher circadian variation of $H R$ group was significantly associated with 30-day mortality (hazard ratio, 1.260; 95\% CI, 1.064$1.491 ; P=0.007$ ) and 1-year mortality (hazard ratio, 1.207; 95\% CI, 1.057-1.378; $P=0.005$ ) (Table 3).

\section{Interaction analysis}

Considering the SOFA score to be a strong predictor of mortality in ICU patients, the interaction effect between the circadian variation of HR and the SOFA score was also analyzed. The results revealed no interaction between them $(P>0.05)$, which verified the absence of synergistic or antagonistic effect between the two in the prediction of mortality and showed that they were independent of each other in predicting mortality. 
Table 1 Baseline Characteristics of the Study Subjects

\begin{tabular}{|c|c|c|c|}
\hline Characteristics & Group A $(\leq 1)$ & Group B (> 1) & $P$ value \\
\hline Subjects & 2289 & 2471 & \\
\hline Age ( $\geq 65$ yr), n (\%) & $594(26.0)$ & $662(26.8)$ & 0.511 \\
\hline Male, n (\%) & $1293(56.6)$ & $1363(55.2)$ & 0.346 \\
\hline Ethnicity, n (\%) & & & 0.295 \\
\hline White & $1583(69.2)$ & $1664(67.3)$ & \\
\hline Asian & $56(2.4)$ & $69(2.8)$ & \\
\hline Black & $162(7.1)$ & $209(8.5)$ & \\
\hline Hispanic/Latino & $100(4.4)$ & $96(3.9)$ & \\
\hline Unknown/Other & $388(17.0)$ & $433(17.5)$ & \\
\hline Day 1 SOFA score & $4.00(2.00,7.00)$ & $5.00(2.00,8.00)$ & 0.001 \\
\hline Day 1 SAPS-I score & $12.00(8.00,16.00)$ & $12.00(9.00,16.00)$ & 0.006 \\
\hline \multicolumn{4}{|l|}{ Diagnosed by ICD, 9th Editor, $\mathrm{n}(\%)$} \\
\hline Respiratory failure, n (\%) & $313(13.7)$ & $337(13.6)$ & 0.971 \\
\hline Renal failure, n (\%) & $364(16.0)$ & $486(19.7)$ & 0.001 \\
\hline Liver cirrhosis, n (\%) & $115(5.0)$ & $144(5.8)$ & 0.222 \\
\hline Shock, n (\%) & $142(6.2)$ & $152(6.2)$ & 0.940 \\
\hline Diabetes uncomplicated, n (\%) & $224(9.8)$ & $282(11.4)$ & 0.069 \\
\hline Diabetes complicated, n (\%) & $49(2.1)$ & $75(3.0)$ & 0.053 \\
\hline AIDS, n (\%) & $22(1.0)$ & $31(1.3)$ & 0.335 \\
\hline Lymphoma, n (\%) & $25(1.1)$ & $39(1.6)$ & 0.146 \\
\hline Metastatic cancer, n (\%) & $134(5.9)$ & $160(6.5)$ & 0.375 \\
\hline Coagulopathy, n (\%) & $129(5.7)$ & $167(6.8)$ & 0.109 \\
\hline Rheumatoid arthritis, n (\%) & $25(1.1)$ & $37(1.5)$ & 0.218 \\
\hline Infection, n (\%) & $235(10.3)$ & $282(11.4)$ & 0.204 \\
\hline Poisoning, n (\%) & $131(5.7)$ & $99(4.0)$ & 0.006 \\
\hline Hypoferric anemia, n (\%) & $231(10.1)$ & $271(11.0)$ & 0.327 \\
\hline \multicolumn{4}{|c|}{ Related medication taking in day $1, \mathrm{n}(\%)$} \\
\hline Sedatives, n (\%) & $42(1.8)$ & $67(2.7)$ & 0.043 \\
\hline Opioid analgesics, n (\%) & $29(1.3)$ & $61(2.5)$ & 0.002 \\
\hline Catecholamine, n (\%) & $199(8.7)$ & $267(10.8)$ & 0.014 \\
\hline$\beta$-blocking agent, n (\%) & $8(0.3)$ & $7(0.3)$ & 0.889 \\
\hline Length of stay in ICU, day & $2.31(1.54,4.26)$ & $2.52(1.69,4.96)$ & 0.001 \\
\hline First 24-h mean HR & $87.59(77.11,99.25)$ & $88.78(77.21,100.14)$ & 0.119 \\
\hline \multicolumn{4}{|l|}{ Mortality, n (\%) } \\
\hline ICU mortality, n (\%) & $151(6.6)$ & $238(9.6)$ & $<0.001$ \\
\hline Hospital mortality, n (\%) & $200(8.7)$ & $305(12.3)$ & $<0.001$ \\
\hline 30-day mortality, n (\%) & $235(10.3)$ & $344(13.9)$ & $<0.001$ \\
\hline 1-year mortality, n (\%) & $395(17.3)$ & $522(21.1)$ & 0.001 \\
\hline \multicolumn{4}{|l|}{ Follow time, day } \\
\hline 30-day mortality, day & $27.97 \pm 6.44$ & $27.13 \pm 7.60$ & $<0.001$ \\
\hline 1-year mortality, day & $312.85 \pm 119.66$ & $299.84 \pm 131.72$ & $<0.001$ \\
\hline
\end{tabular}

SOFA Sequential Organ Failure Assessment, SAPS-I Simplified Acute Physiology Score-I, ICD International Classification of Diseases, AIDS Acquired Immune Deficiency Syndrome

\section{Sensitivity analysis}

To diminish the influence of severity-of-illness on mortality from clinical practice, all individuals were also divided into two subgroups based on the median SOFA score of all the included patients: lower SOFA score group $(0 \leq$ SOFA score $\leq 5)$ and higher SOFA score group $(6 \leq$ SOFA score $\leq 24)$. Interestingly, in the higher SOFA score subgroup, taking group $A$ as a reference, group B showed a remarkable association with short-term and long-term mortality in the 
Table 2 Baseline Characteristics of the factors associated with ICU mortality and ICU survival

\begin{tabular}{|c|c|c|c|}
\hline Characteristics & ICU mortality & ICU survival & $P$ value \\
\hline Subjects & 389 & 4371 & \\
\hline Age ( $\geq 65$ yr), n (\%) & $164(42.2)$ & $1092(25.0)$ & $<0.001$ \\
\hline Male, n (\%) & $214(55.0)$ & $2442(55.9)$ & 0.771 \\
\hline Ethnicity, n (\%) & & & $<0.001$ \\
\hline White & $247(63.5)$ & $3000(68.6)$ & \\
\hline Asian & $7(1.8)$ & $118(2.7)$ & \\
\hline Black & $25(6.4)$ & $346(7.9)$ & \\
\hline Hispanic/Latino & $5(1.3)$ & $191(4.4)$ & \\
\hline Unknown/Other & $105(27.0)$ & $716(16.4)$ & \\
\hline Day 1 SOFA score & $10.00(7.00,14.00)$ & $4.00(2.00,7.00)$ & $<0.001$ \\
\hline Day 1 SAPS-I score & $19.00(15.00,23.00)$ & $12.00(8.00,15.00)$ & $<0.001$ \\
\hline \multicolumn{4}{|l|}{ Diagnosed by ICD, 9th Editor, n (\%) } \\
\hline Respiratory failure, n (\%) & $187(48.1)$ & $463(10.6)$ & $<0.001$ \\
\hline Renal failure, n (\%) & $172(44.2)$ & $678(15.5)$ & $<0.001$ \\
\hline Liver cirrhosis, n (\%) & $61(15.7)$ & $198(4.5)$ & $<0.001$ \\
\hline Shock, n (\%) & $86(22.1)$ & $208(4.8)$ & $<0.001$ \\
\hline Diabetes uncomplicated, n (\%) & $52(11.3)$ & $454(10.4)$ & 0.068 \\
\hline Diabetes complicated, n (\%) & $5(1.3)$ & $119(2.7)$ & 0.088 \\
\hline AIDS, n (\%) & $6(2.8)$ & $47(1.2)$ & 0.556 \\
\hline Lymphoma, n (\%) & $11(12.6)$ & $53(5.6)$ & 0.008 \\
\hline Metastatic cancer, n (\%) & $49(5.9)$ & $245(6.5)$ & $<0.001$ \\
\hline Coagulopathy, n (\%) & $48(12.3)$ & $248(5.7)$ & $<0.001$ \\
\hline Rheumatoid arthritis, n (\%) & $5(1.3)$ & $57(1.3)$ & 0.974 \\
\hline Infection, n (\%) & $43(11.1)$ & $474(10.8)$ & 0.899 \\
\hline Poisoning, n (\%) & $6(1.5)$ & $224(5.1)$ & 0.002 \\
\hline Hypoferric anemia, n (\%) & $35(9.0)$ & $467(10.7)$ & 0.298 \\
\hline \multicolumn{4}{|c|}{ Related medication taking in day $1, \mathrm{n}(\%)$} \\
\hline Sedatives, n (\%) & $21(5.4)$ & $88(2.0)$ & $<0.001$ \\
\hline Opioid analgesics, n (\%) & $20(5.1)$ & $70(1.6)$ & $<0.001$ \\
\hline Catecholamine, n (\%) & $98(25.2)$ & $368(8.4)$ & $<0.001$ \\
\hline$\beta$-blocking agent, n (\%) & $1(0.3)$ & $12(0.3)$ & 1.000 \\
\hline Length of stay in ICU, day & $5.04(2.31,9.94)$ & $2.30(1.58,4.20)$ & $<0.001$ \\
\hline Circadian variation of HR & $1.00(0.94,1.06)$ & $0.98(0.93,1.04)$ & $<0.001$ \\
\hline First 24-h mean HR & $94.45(81.07,107.39)$ & $87.81(76.94,99.07)$ & $<0.001$ \\
\hline
\end{tabular}

SOFA Sequential Organ Failure Assessment, SAPS-I Simplified Acute Physiology Score-I, ICD International Classification of Diseases, AIDS Acquired Immune Deficiency Syndrome

multivariable regression model after adjusting a series of covariates. The specific statistical results were as follows: ICU mortality: OR, 1.444, 95\% CI, 1.084-1.924, $P=0.012$; hospital mortality: OR, 1.442 , 95\% CI, $1.110-$ 1.873, $P=0.006$; 30 -day mortality: hazard ratio, 1.331 , 95\% CI, 1.091-1.624, $P=0.005$; 1-year mortality: hazard ratio, 1.263 , 95\% CI, $1.069-1.493, P=0.006$. However, in the lower SOFA score subgroup, there was no statistical significance between the circadian variation of HR and mortality (Table 4). Kaplan-Meier survival curves also revealed that the short-term as well as longterm probability of survival was higher in group A than that in group B in the higher SOFA score subgroup (Fig. 2).

\section{Discussion}

In this study, we investigated the relationship between circadian variation of HR and mortality in ICU patients. Our results show that patients with a higher circadian variation of HR had higher ICU mortality, hospital mortality, 30-day mortality and 1-year mortality than that in patients with a lower circadian variation of HR after adjusting for demographic parameters, clinical comorbidities, medications affecting heart rate, severity scoring 


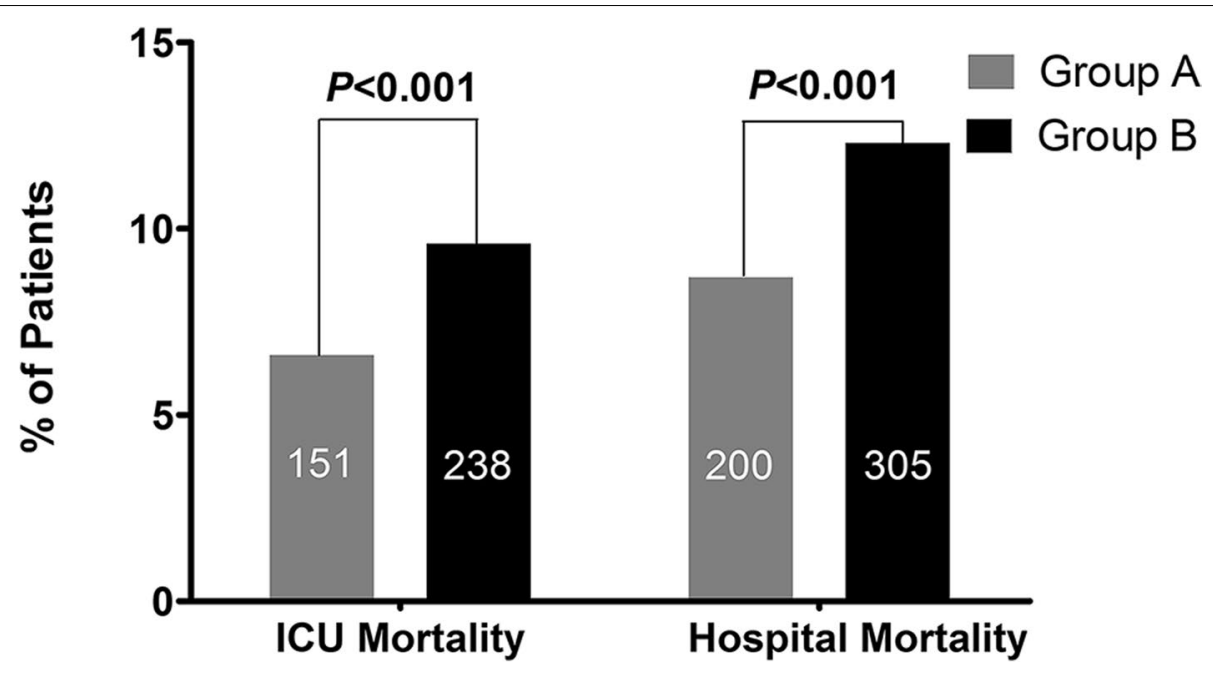

Fig. 1 The difference in ICU and hospital mortality in patients with different circadian variation of HR. Patients in group B had higher ICU $(P<0.001)$ and hospital mortality $(P<0.001)$ than patients in group A

Table 3 Association of circadian variation of heart rate with Mortality in Overall Patients

\begin{tabular}{|c|c|c|c|c|c|c|}
\hline \multirow[t]{2}{*}{ Logistic Regression } & \multicolumn{3}{|l|}{ ICU mortality } & \multicolumn{3}{|l|}{ Hospital mortality } \\
\hline & OR & $95 \% \mathrm{Cl}$ & P & OR & $95 \% \mathrm{Cl}$ & $P$ \\
\hline Model 1 & 1.471 & $1.218-1.775$ & $<0.001$ & 1.471 & $1.218-1.775$ & $<0.001$ \\
\hline Model 2 & 1.463 & $1.210-1.768$ & $<0.001$ & 1.463 & $1.210-1.768$ & $<0.001$ \\
\hline Model 3 & 1.470 & $1.192-1.813$ & $<0.001$ & 1.470 & $1.192-1.813$ & $<0.001$ \\
\hline Model 4 & 1.417 & $1.146-1.752$ & 0.001 & 1.417 & $1.146-1.752$ & 0.001 \\
\hline Model 5 & 1.398 & $1.116-1.750$ & 0.003 & 1.398 & $1.116-1.750$ & 0.003 \\
\hline Model 6 & 1.397 & $1.115-1.748$ & 0.004 & 1.397 & $1.115-1.748$ & 0.004 \\
\hline Model 7 & 1.393 & $1.112-1.745$ & 0.004 & 1.393 & $1.112-1.745$ & 0.004 \\
\hline \multirow{2}{*}{$\begin{array}{l}\text { Cox } \\
\text { Regression }\end{array}$} & \multicolumn{3}{|l|}{ 30-day mortality } & \multicolumn{3}{|l|}{ 1-year mortality } \\
\hline & $\mathrm{HR}$ & $95 \% \mathrm{Cl}$ & P & $H R$ & $95 \% \mathrm{Cl}$ & P \\
\hline Model 1 & 1.387 & $1.175-1.638$ & $<0.001$ & 1.261 & $1.107-1.438$ & $<0.001$ \\
\hline Model 2 & 1.376 & $1.165-1.624$ & $<0.001$ & 1.254 & $1.100-1.429$ & 0.001 \\
\hline Model 3 & 1.341 & $1.135-1.586$ & 0.001 & 1.253 & $1.098-1.430$ & 0.001 \\
\hline Model 4 & 1.307 & $1.105-1.546$ & 0.002 & 1.233 & $1.081-1.408$ & 0.002 \\
\hline Model 5 & 1.294 & $1.094-1.531$ & 0.003 & 1.218 & $1.067-1.390$ & 0.003 \\
\hline Model 6 & 1.277 & $1.079-1.510$ & 0.004 & 1.212 & $1.062-1.383$ & 0.004 \\
\hline Model 7 & 1.260 & $1.064-1.491$ & 0.007 & 1.207 & $1.057-1.378$ & 0.005 \\
\hline
\end{tabular}

Model 1 unadjusted

Model 2 adjusted for age, gender, and ethnicity

Model 3 adjusted for Model 2 plus Respiratory failure, Renal failure, Liver cirrhosis, Shock, Diabetes uncomplicated, Diabetes complicated, AIDS, Lymphoma, Metastatic cancer, Coagulopathy, Rheumatoid arthritis, Infection, Poisoning, and Hypoferric anemia

Model 4 adjusted for Model 3 plus Medication taking in day 1 (including sedatives, catecholamine, $\beta$-blockers, Opioid analgesics)

Model 5 adjusted for Model 4 plus Sequential Organ Failure Assessment, and Simplified Acute Physiology Score-I

Model 6 adjusted for Model 5 plus length of stay in ICU

Model 7 adjusted for Model 6 plus average heart rate in the first $24 \mathrm{~h}$

systems including SAPS-I and SOFA score, length of stay in the ICU, and the first 24-h average HR.

A circadian pattern was observed in the variation of many biological and psychological processes, most of which comply a rhythmically change with a period length of approximately $24 \mathrm{~h}$. Previous studies have reported the existence of circadian variations in cognitive functions $[27,28]$ as well as the underlying brain processes $[29]$ in 
Table 4 Association of circadian variation of heart rate with Mortality in different SOFA score subgroups

\begin{tabular}{cllll}
\hline & ICU mortality & Hospital mortality & 30-day mortality & 1-year mortality \\
\hline SOFA score (0-5) & OR $(95 \% \mathrm{Cl})$ & $\mathrm{OR}(95 \% \mathrm{Cl})$ & $\mathrm{HR}(95 \% \mathrm{Cl})$ & $\mathrm{HR}(95 \% \mathrm{Cl})$ \\
Model 1 & $1.180(0.703-1.980)$ & $1.175(0.784-1.761)$ & $1.078(0.782-1.484)$ & $1.099(0.884-1.366)$ \\
Model 2 & $1.157(0.688-1.947)$ & $1.155(0.769-1.735)$ & $1.056(0.767-1.455)$ & $1.086(0.874-1.350)$ \\
Model 3 & $1.385(0.794-2.416)$ & $1.295(0.841-1.992)$ & $1.113(0.806-1.538)$ & $1.096(0.880-1.364)$ \\
Model 4 & $1.385(0.791-2.425)$ & $1.280(0.830-1.975)$ & $1.100(0.796-1.521)$ & $1.086(0.872-1.353)$ \\
Model 5 & $1.482(0.813-2.642)$ & $1.345(0.860-2.104)$ & $1.108(0.799-1.535)$ & $1.062(0.852-1.325)$ \\
Model 6 & $1.416(0.792-2.534)$ & $1.304(0.833-2.043)$ & $1.099(0.793-1.525)$ & $1.049(0.840-1.308)$ \\
Model 7 & $1.534(0.848-2.777)$ & $1.359(0.863-2.138)$ & $1.162(0.836-1.617)$ & $1.053(0.844-1.315)$ \\
SOFA score (6-24) & OR (95\% Cl) & OR (95\% CI) & HR (95\% Cl) & HR (95\% CI) \\
Model 1 & $1.493(1.171-1.903)$ & $1.481(1.185-1.851)$ & $1.436(1.181-1.745)$ & $1.301(1.104-1.533)$ \\
Model 2 & $1.492(1.168-1.906)$ & $1.483(1.184-1.857)$ & $1.434(1.180-1.743)$ & $1.306(1.108-1.539)$ \\
Model 3 & $1.480(1.134-1.932)$ & $1.487(1.163-1.901)$ & $1.414(1.160-1.722)$ & $1.318(1.117-1.557)$ \\
Model 4 & $1.445(1.104-1.889)$ & $1.453(1.135-1.861)$ & $1.390(1.141-1.695)$ & $1.296(1.097-1.531)$ \\
Model 5 & $1.453(1.091-1.935)$ & $1.457(1.122-1.891)$ & $1.380(1.132-1.682)$ & $1.289(1.091-1.522)$ \\
Model 6 & $1.453(1.091-1.936)$ & $1.457(1.122-1.891)$ & $1.355(1.111-1.652)$ & $1.274(1.078-1.504)$ \\
Model 7 & $1.444(1.084-1.924)$ & $1.442(1.110-1.873)$ & $1.331(1.091-1.624)$ & $1.263(1.069-1.493)$ \\
\hline
\end{tabular}

Model 1 unadjusted

Model 2 adjusted for age, gender, and ethnicity

Model 3 adjusted for Model 2 plus Respiratory failure, Renal failure, Liver cirrhosis, Shock, Diabetes uncomplicated, Diabetes complicated, AIDS, Lymphoma, Metastatic cancer, Coagulopathy, Rheumatoid arthritis, Infection, Poisoning, and Hypoferric anemia

Model 4 adjusted for Model 3 plus Medication taking in day 1 (including sedatives, catecholamine, $\beta$-blockers, Opioid analgesics)

Model 5 adjusted for Model 4 plus Sequential Organ Failure Assessment, and Simplified Acute Physiology Score-I

Model 6 adjusted for Model 5 plus length of stay in ICU

Model 7 adjusted for Model 6 plus average heart rate in the first $24 \mathrm{~h}$

healthy individuals. Recently, there's growing interest in the research of disturbed circadian rhythms in patients situated in special environments settings without clearly delineated day or night, such as ICUs or long-term care homes [23, 30, 31]. Patients from ICUs commonly suffer from impaired sleep quality, which may result from the unnatural light rhythm and light intensity, further leading to impaired immune responses and ability of recovery from illness [23, 32], ultimately causing different prognosis.

Paul and Lemmer showed that the 24-h profile parameters, including cortisol, blood pressure, HR, body temperature, and spontaneous motor activity, were all disturbed in 24 critically ill sedated patients compared with the normal rhythmic 24-h patterns in healthy controls [21]. However, clinical complications that occur when circadian rhythms are disturbed have been generally unappreciated, especially in ICU patients. Therefore, our team has been working on the study of the influence of circadian rhythms of physiological signals on the prognosis of ICU patients. Previous research has found that reduced circadian fluctuations of mean arterial pressure were associated with hospital mortality and ICU mortality among critically ill patients [33]. Besides, we also found that rise in the nocturnal mean arterial pressure within the first $24 \mathrm{~h}$ of admission might serve as an independent risk factor for short-term and long-term mortality; this may help in early risk stratification and personalized mean arterial pressure management in the ICU [34].

Previous studies have reported multiple HR variations. Among them, HRV, a temporal beat-to-beat variation in successive RR intervals on an electrocardiographic (ECG) recording, was considered as a reflection of the regulation of HR by the autonomic nervous system [35]. In recent years, the prognostic value of HRV was evaluated outside a specific cardiological context. The reduction in HRV was associated with a higher mortality in critically ill patients as reported in several studies [36]. More specifically, descending HRV was found as a common feature in septic patients. Especially, impaired sympathetic modulation, represented by low frequency power in spectrum analysis of HRV, could be the early marker of MODS for ICU patients with sepsis [8]. In addition, the low-/highfrequency power ratio in spectrum analysis of HRV, considered as a representation of sympathovagal imbalance, may predict early clinical deterioration [9], providing an early indication for the identification of impending septic shock among emergency department patients [10]. In the meantime, upon ICU admission, a short-term reduction 

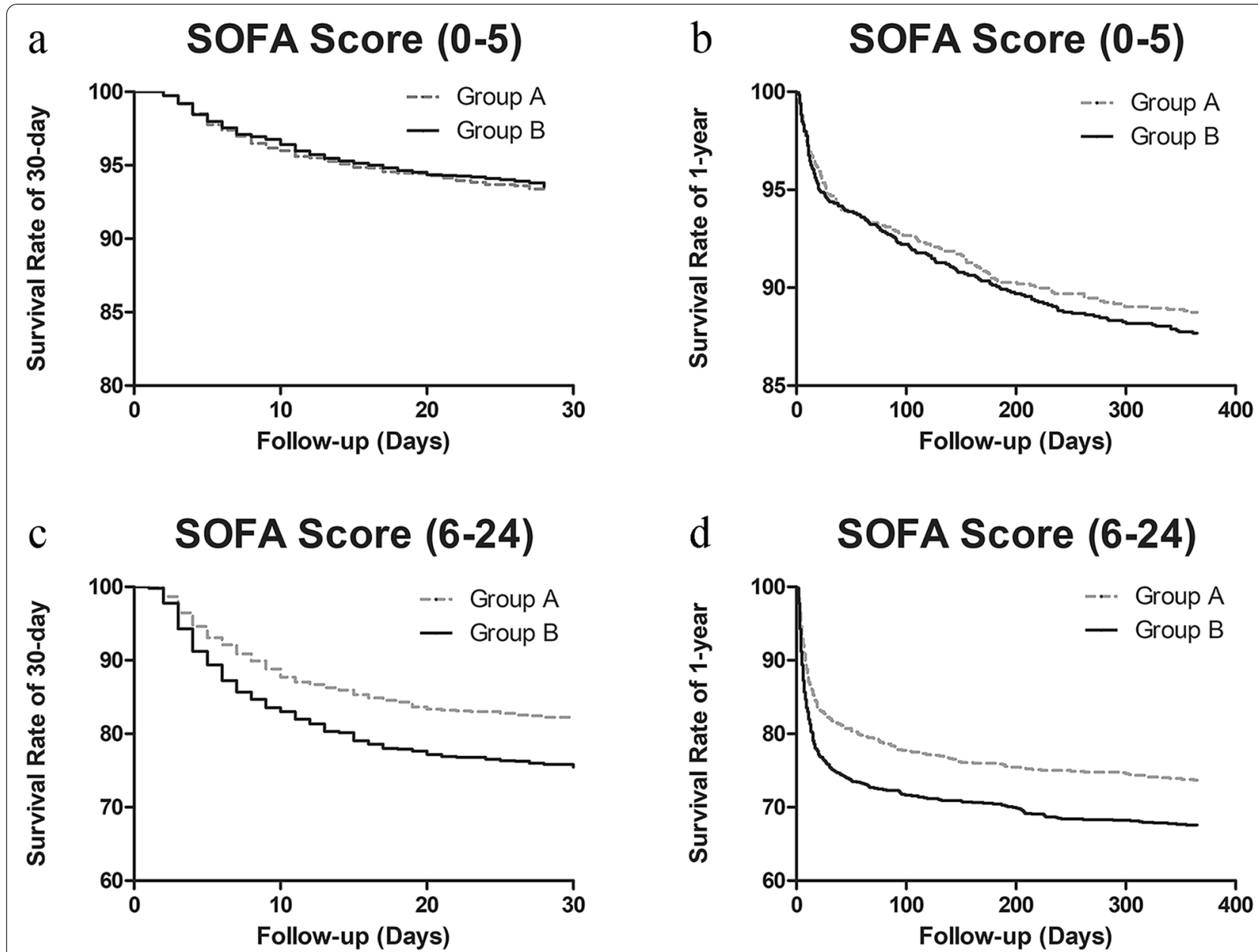

Fig. 2 Kaplan-Meier survival analysis plot for mortality with different circadian variation of HR. Patients in group B had lower rates of 30-day (c) $(P<0.001)$ and 1-year (d) $(P<0.001)$ survival than patients in group A in the higher SOFA score subgroups. However, in the lower SOFA score subgroup, there was no statistical significance between the circadian variation of HR and 30-day (a) and 1-year (b) mortality

of HRV was also reported as a predictive factor for the mortality in septic patients [37].

HRT is another parameter that describes the physiological short-term oscillation of beat-to-beat intervals after spontaneous ventricular premature beats [38]. HRT also could independently predict cardiac mortality in patients with diabetes mellitus or simple ischemic heart disease [12, 39]. Notably, a meta-analysis reveals that elevated resting $\mathrm{HR}$, an indicator of myocardial oxygen consumption, may increase the mortality of acute coronary syndrome patients in the coronary intervention era [40]. Besides, a cohort study on the Japanese general population reports that nighttime mean HR is associated with increased risk of all-cause mortality in epidemiological settings [18]. Furthermore, by using pervasive sensing technology and artificial intelligence in ICU, the autonomous and granular monitoring system presented that the delirious patients in ICU had higher average heart rate
[41]. These indices can be easily calculated from a 24-h Holter ECG. An increasing amount of evidence also supports the association of these parameters with adverse outcomes [42].

In this study, the circadian variation in $\mathrm{HR}$ was proposed as a powerful parameter for assessing HR change and emphasizes the circadian rhythm, which should be able to better predict the occurrence of adverse events combined with previous parameters in critically ill patients. In normal conditions, the circadian decline rate of $\mathrm{HR}$ is within $10 \%-20 \%$, called the nocturnal dipping of HR, and is mostly determined by the endogenous neuroendocrine rhythm [18, 43]. Critically ill patients experience circumstance alterations in light-dark cycles, auditory disruption, iatrogenic treatment, and psychological reactions when they are admitted to the ICU. These external changes disturb the endogenous neuroendocrine rhythm and sleep-wake cycle, which may 
contribute to the nocturnal non-dipping or anti-dipping of $\mathrm{HR}$. The nighttime higher HR or reduced dipping of sleep HR can represent the status of sympathetic overdrive. On the one hand, higher nighttime HR caused by sympathetic overdrive could be associated with insulin resistance or direct atherosclerotic lesions via hemodynamic disturbances $[44,45]$. On the other hand, sleep HR was a better marker of mortality than awake or clinical HR [46]. Therefore, we proposed that circadian variations of HR (calculated as the ratio of NHR to daytime mean HR) reflected impaired autonomic nerve regulation. Abnormal circadian variation of HR might be associated with adverse prognosis.

The SOFA score is an acknowledged parameter that is robustly correlated with patient outcomes in the ICU setting [25]. Therefore, we also conducted a sensitivity analysis in which the patients were divided into two subgroups according to the median of SOFA scores. Surprisingly, the association between circadian variation of HR and mortality persisted in the higher SOFA score subgroup but not in the lower after adjusting for a series of variables. The regression analysis verified the association of circadian variation of HR with mortality again. Therefore, a higher circadian fluctuation of HR might serve as an independent risk factor for both short-term mortality and long-term mortality in critically ill patients, especially in the higher SOFA score individuals.

The main strength of our study is the high number of general ICU patients included. To our knowledge, this is the first report that circadian variation of HR is associated with short-term mortality and long-term mortality in ICU patients. The results reveal the importance of circadian rhythm in ICU patient management, which reminds the clinicians to attach great importance to the changes of the circadian rhythm parameters in ICU patients and reduce the external disturbance at nighttime; besides, considering that cardiovascular disease could have a significant effect on HR or HR variations, and the mechanism between them has been not well understood, we excluded these patients to reduce interference of confounding factors. It is important to carry out risk stratification in the early stage to reduce the mortality rate and improve the prognosis of ICU patients.

Several limitations of this study warrant discussion. Firstly, limited by the observational design, causal conclusions cannot be reached. However, a wide range of clinically important confounders were included to reach valid results. Secondly, based on data from a single academic medical center, the applicability of our findings was limited in other sites. Thirdly, confined by the availability of data, SAPS I score, instead of SAPS II, was adopted in the present study in assessing the disease severity along with SOFA score. Fourthly, the MIMIC II database is relatively old. We will continue to mine the updated MIMIC database in the subsequent study to further verify our research results. Finally, as limitations of a retrospective study, undetected potential confounders may also exist. Although multivariable models were adjusted for as many confounding factors as possible to diminish the possible influences, residual confounding factors may still exist and need to be investigated in the future.

\section{Conclusions}

The present study revealed the short-term and long-term prognostic value of the higher circadian variation of $\mathrm{HR}$ among critically ill patients, especially in individuals with higher SOFA scores. Therefore, the circadian variation of $\mathrm{HR}$, as a cost-effective and readily available parameter, may serve as a potentially indicator of prognosis in the management of ICU patients. For the clinicians, further management, such as reducing the number of operations, reducing ward noise, or lowering light intensity level at night, may be considered to improve the circadian HR rhythm of ICU patients to improve their prognosis. Certainly, our findings are also needed to be confirmed by future studies, especially large prospective studies with a longer follow-up.

\section{Abbreviations \\ AIDS: Acquired immune deficiency syndrome; Cl: Confidence interval; ECG: Electrocardiographic; HR: Heart rate; HRT: Heart rate turbulence; HRV: Heart rate variability; ICD: International Classification of Diseases-9 diagnoses; ICU: Intensive care units; MIMIC-II: Multiparameter Intelligent Monitoring in Inten- sive Care II; MIT: Massachusetts Institute of Technology; MODS: Multiple organ dysfunction syndrome; NHR: Nighttime mean heart rate; OR: Odds ratio; RHR: Resting heart rate; SAPS-I: Simplified Acute Physiology Score-l; SD: Standard deviation; SOFA: Sequential Organ Failure Assessment.}

\section{Supplementary Information}

The online version contains supplementary material available at https://doi. org/10.1186/s12871-022-01586-9.

Additional file 1: Table 1. The ICU admission types of the present study subjects.

Additional file 2: Table 2. The univariate analysis of factors associate ICU, hospital mortality in the wholepopulations.

Additional file 3: Table 3. The univariate analysis of factors associate 30-day and 1-year in the whole populations.

\section{Acknowledgements}

We appreciate the researchers at the MIT Laboratory for Computational Physiology and collaborating research groups to keep MIMIC-II databases available.

\section{Authors' contributions}

$X C W, J J Z$, and LYD take responsibility for the integrity of the data, interpretation, and analysis. XCW, JJZ, LYD, JML, RHL, XTJ, JJR and YG contributed substantially to the study design, data interpretation, and writing of the manuscript. XCW, JJZ, and LYD performed the statistical analysis and data synthesis. All authors approved the final version of the manuscript. 


\section{Funding}

This study was funded by the National Natural Science Foundation of China (81670049).

\section{Availability of data and materials}

The datasets used and/or analyzed during the current study are available from the corresponding author on reasonable request.

\section{Declarations}

\section{Ethics approval and consent to participate}

All procedures performed in studies involving human participants were in accordance with the ethical standards of the institutional research committee (Cardif Metropolitan University ethics committee-17/4/02R) and with the 1964 Helsinki Declaration and its later amendments or comparable ethical standards. Because the project did not impact clinical care and all protected health information was deidentified, informed consent was waived for the present study by the Institutional Review Board from the Second Affiliated Hospital of Xi'an Jiaotong University. The study was designed and conducted in accordance with relevant guidelines and regulations (Declaration of Helsinki), and the study protocol was approved by Institutional Review Board from the Second Affiliated Hospital of Xi'an Jiaotong University.

\section{Consent for publication}

Consent for publication is not applicable.

\section{Competing interests}

The authors declare that they have no known competing financial interests or personal relationships that could have appeared to influence the work reported in this paper.

Received: 22 October 2021 Accepted: 8 February 2022

Published online: 12 February 2022

\section{References}

1. Camm AJ, Malik M, Bigger JT, Breithardt G, Cerutti S, Cohen RJ, et al. Heart rate variability: standards of measurement, physiological interpretation and clinical use. Task force of the European society of cardiology and the North American society of pacing and electrophysiology. Circulation. 1996;93(5):1043-65.

2. Kleiger RE, Stein PK, Bigger JT. Heart rate variability: measurement and clinical utility. Ann Noninvasive Electrocardiol. 2005;10(1):88-101.

3. Goldstein B, Fiser DH, Kelly MM, Mickelsen D, Ruttimann U, Pollack MM. Decomplexification in critical illness and injury: relationship between heart rate variability, severity of illness, and outcome. Crit Care Med. 1998;26(2):352-7.

4. Winchell RJ, Hoyt DB. Spectral analysis of heart rate variability in the ICU: a measure of autonomic function. J Surg Res. 1996;63(1):11-6.

5. Yien HW, Hseu SS, Lee LC, Kuo TB, Lee TY, Chan SH. Spectral analysis of systemic arterial pressure and heart rate signals as a prognostic tool for the prediction of patient outcome in the intensive care unit. Crit Care Med. 1997;25(2):258-66.

6. Godin PJ, Fleisher LA, Eidsath A, Vandivier RW, Preas HL, Banks SM, et al. Experimental human endotoxemia increases cardiac regularity: results from a prospective, randomized, crossover trial. Crit Care Med. 1996;24(7):1117-24.

7. Annane D, Trabold F, Sharshar T, Jarrin I, Blanc AS, Raphael JC, et al. Inappropriate sympathetic activation at onset of septic shock: a spectral analysis approach. Am J Respir Crit Care Med. 1999;160(2):458-65.

8. Pontet J, Contreras P, Curbelo A, Medina J, Noveri S, Bentancourt S, et al. Heart rate variability as early marker of multiple organ dysfunction syndrome in septic patients. J Crit Care. 2003;18(3):156-63.

9. Barnaby D, Ferrick K, Kaplan DT, Shah S, Bijur P, Gallagher EJ. Heart rate variability in emergency department patients with sepsis. Acad Emerg Med. 2002;9(7):661-70.

10. Chen WL, Kuo CD. Characteristics of heart rate variability can predict impending septic shock in emergency department patients with sepsis. Acad Emerg Med. 2007;14(5):392-7.
11. Monfredi O, Lyashkov AE, Johnsen AB, Inada S, Schneider H, Wang R, et al. Biophysical characterization of the underappreciated and important relationship between heart rate variability and heart rate. Hypertension. 2014;64(6):1334-43.

12. Miwa Y, Miyakoshi M, Hoshida K, Yanagisawa R, Abe A, Tsukada T, et al. Heart rate turbulence can predict cardiac mortality following myocardial infarction in patients with diabetes mellitus. J Cardiovasc Electrophysiol. 2011;22(10):1135-40.

13. Stein PK, Barzilay Jl. Relationship of abnormal heart rate turbulence and elevated CRP to cardiac mortality in low, intermediate, and high-risk older adults. J Cardiovasc Electrophysiol. 2011;22(2):122-7.

14 Grander W, Mullauer K, Koller B, Tilg H, Dunser M. Heart rate before ICU discharge: a simple and readily available predictor of short- and longterm mortality from critical illness. Clin Res Cardiol. 2013;102(8):599-606.

15. Hoke RS, Muller-Werdan U, Lautenschlager C, Werdan K, Ebelt H. Heart rate as an independent risk factor in patients with multiple organ dysfunction: a prospective, observational study. Clin Res Cardiol. 2012;101(2):139-47.

16. Shashikumar SP, Stanley MD, Sadiq I, Li Q, Holder A, Clifford GD, et al. Early sepsis detection in critical care patients using multiscale blood pressure and heart rate dynamics. J Electrocardiol. 2017;50(6):739-43.

17. Sandfort V, Johnson AEW, Kunz LM, Vargas JD, Rosing DR. Prolonged elevated heart rate and 90-day survival in acutely III patients: data from the MIMIC-III database. J Intensive Care Med. 2018;34(8):622-9.

18. A H, Inoue R, Ohkubo T, Kikuya M, Metoki H, Asayama K, et al. Predictive value of ambulatory heart rate in the Japanese general population: the Ohasama study. J Hypertens. 2008;26(8):1571-6.

19 Hasanpour Mir M, Yousefshahi F, Abdollahi M, Ahmadi A, Nadjafi A, Mojtahedzadeh $M$. The predictive value of resting heart rate following osmotherapy in brain injury: back to basics. DARU. 2012;20(1):102.

20 Gazendam JAC, Van Dongen HPA, Grant DA, Freedman NS, Zwaveling $\mathrm{JH}$, Schwab RJ. Altered circadian rhythmicity in patients in the ICU. Chest. 2013;144(2):483-9.

21. Paul T, Lemmer B. Disturbance of circadian rhythms in analgosedated intensive care unit patients with and without craniocerebral injury. Chronobiol Int. 2007;24(1):45-61.

22 Korompeli A, Muurlink O, Kavrochorianou N, Katsoulas T, Fildissis G, Baltopoulos G. Circadian disruption of ICU patients: a review of pathways, expression, and interventions. J Crit Care. 2017;38:269-77.

23 Telias I, Wilcox ME. Sleep and circadian rhythm in critical illness. Crit Care. 2019;23(1):82.

24. Saeed M, Villarroel M, Reisner AT, Clifford G, Lehman LW, Moody G, et al. Multiparameter Intelligent Monitoring in Intensive Care II: a public-access intensive care unit database. Crit Care Med. 2011;39(5):952-60.

25. Singer M, Deutschman CS, Seymour CW, Shankar-Hari M, Annane D, Bauer $M$, et al. The third international consensus definitions for sepsis and septic shock (Sepsis-3). JAMA. 2016;315(8):801-10.

26. Zheng CF, Liu WY, Zeng FF, Zheng MH, Shi HY, Zhou Y, et al. Prognostic value of platelet-to-lymphocyte ratios among critically ill patients with acute kidney injury. Crit Care. 2017;21(1):238.

27. Santhi N, Lazar A, McCabe P, Lo J, Groeger JA, Dijk DJ. Sex differences in the circadian regulation of sleep and waking cognition in humans. Proc Natl Acad Sci U S A. 2016:113(19):E2730-9.

28 Schmidt C, Collette F, Cajochen C, Peigneux P. A time to think: circadian rhythms in human cognition. Cogn Neuropsychol. 2007;24(7):755-89.

29. Muto V, Jaspar M, Meyer C, Kussé C, Chellappa SL, Degueldre C, et al. Local modulation of human brain responses by circadian rhythmicity and sleep debt. Science. 2016;353(6300):687-90.

30. Patel M, Chipman J, Carlin BW, Shade D. Sleep in the intensive care unit setting. Crit Care Nurs Q. 2008;31(4):309-18 quiz 319-20.

31. van Someren EJ, Hagebeuk EE, Lijzenga C, Scheltens P, de Rooij SE, Jonker C, et al. Circadian rest-activity rhythm disturbances in alzheimer's disease. Biol Psychiatry. 1996;40(4):259-70.

32 Bryant PA, Trinder J, Curtis N. Sick and tired: does sleep have a vital role in the immune system? Nat Rev Immunol. 2004;4(6):457-67.

33. Gao Y, Wang Q, Li J, Zhang J, Li R, Sun L, et al. Impact of mean arterial pressure fluctuation on mortality in critically III patients. Crit Care Med. 2018;46(12):e1167-74.

34. Li J, Li R, Gao Y, Zhang J, Zhao Y, Zhang X, et al. Nocturnal mean arterial pressure rising is associated with mortality in the intensive care unit: a retrospective cohort study. J Am Heart Assoc. 2019;8(19):e012388. 
35 Nicolini P, Ciulla MM, De Asmundis C, Magrini F, Brugada P. The prognostic value of heart rate variability in the elderly, changing the perspective: from sympathovagal balance to chaos theory. Pacing Clin Electrophysiol. 2012;35(5):622-38.

36. de Castilho FM, Ribeiro ALP, Nobre V, Barros G.de Sousa MR. Heart rate variability as predictor of mortality in sepsis: a systematic review. PLoS One. 2018;13(9):e0203487.

37. de Castilho FM, Ribeiro ALP, da Silva JLP, Nobre V.de Sousa MR. Heart rate variability as predictor of mortality in sepsis: a prospective cohort study. PLoS One. 2017;12(6):e0180060.

38. Bauer A, Malik M, Schmidt G, Barthel P, Bonnemeier H, Cygankiewicz I, et al. Heart rate turbulence: standards of measurement, physiological interpretation, and clinical use: international society for holter and noninvasive electrophysiology consensus. J Am Coll Cardiol. 2008;52(17):1353-65.

39. Marynissen T, Flore V, Heidbuchel H, Nuyens D, Ector J, Willems R. Heart rate turbulence predicts ICD-resistant mortality in ischaemic heart disease. Europace. 2014;16(7):1069-77.

40. Xu T, Zhan Y, Xiong J, Lu N, He Z, Su X, et al. The relationship between heart rate and mortality of patients with acute coronary syndromes in the coronary intervention era: meta-analysis. Medicine (Baltimore). 2016;95(46):e5371.

41. Davoudi A, Malhotra KR, Shickel B. Intelligent ICU for autonomous patient monitoring using pervasive sensing and deep learning. Sci Rep. 2019;9(1):8020

42. Goldberger JJ, Cain ME, Hohnloser SH, Kadish AH, Knight BP, Lauer MS, et al. American heart association/American college of cardiology foundation/heart rhythm society scientific statement on noninvasive risk stratification techniques for identifying patients at risk for sudden cardiac death: a scientific statement from the American heart association council on clinical cardiology committee on electrocardiography and arrhythmias and council on epidemiology and prevention. Circulation. 2008;1 18(14):1497-518.

43. Shaw E, Tofler GH. Circadian rhythm and cardiovascular disease. Curr Atheroscler Rep. 2009;11(4):289-95.

44. Palatini $\mathrm{P}$, Julius $\mathrm{S}$. Heart rate and the cardiovascular risk. J Hypertens. 1997;15(1):3-17.

45. Palatini $P$, Julius $S$. Association of tachycardia with morbidity and mortality: pathophysiological considerations. J Hum Hypertens. 1997;1 1(Suppl 1):S19-27.

46. Ben-Dov IZ, Kark JD, Ben-Ishay D, Mekler J, Ben-Arie L, Bursztyn M. Blunted heart rate dip during sleep and all-cause mortality. Arch Intern Med. 2007;167(19):2116-21.

\section{Publisher's Note}

Springer Nature remains neutral with regard to jurisdictional claims in published maps and institutional affiliations.

Ready to submit your research? Choose BMC and benefit from:

- fast, convenient online submission

- thorough peer review by experienced researchers in your field

- rapid publication on acceptance

- support for research data, including large and complex data types

- gold Open Access which fosters wider collaboration and increased citations

- maximum visibility for your research: over 100M website views per year

At BMC, research is always in progress.

Learn more biomedcentral.com/submissions 